\title{
Dominique Maingueneau: questões teóricas para análise discursiva na comunicação: cenografia e ethos
}

Dominique Maingueneau: theoretical issues for discursive analysis in communication: scenography and ethos

Dominique Maingueneau: cuestiones teóricas para el análisis discursivo en la comunicación: escenografía y ethos

\section{Entrevista}

Dominique Maingueneau

\section{Entrevistadores}

- Doutor em Letras pela Pontifícia Universidade Católica do Rio Grande do Sul (PUCRS).

- Mestre em Linguística Aplicada pela Universidade do Vale do Rio dos Sinos (Unisinos).

- Professor do Programa de Pós-Graduação em Processos e Manifestações Sociais da Universidade Feevale.

- Professor do Programa de Pós-Graduação em Letras da Universidade de Passo Fundo (UFP).

- E-mail: ernanic@feevale.br

\section{(9) Rudimar Baldissera}

- Doutor em Comunicação Social pela PUCRS.

- Mestre em Ciências da Comunicação/Semiótica pela Unisinos.

- Professor do Departamento de Comunicação da Faculdade de Biblioteconomia e Comunicação da Universidade Federal do Rio Grande do Şul (UFRGS).

- Professor do Programa de Pós-Graduação em Comunicação da UFRGS.

- E-mail: rudimar.baldissera@ufrgs.br 


\section{(9) Fernando Simões Antunes Junior}

- Doutor em Comunicação Social pela PUCRS.

- Mestre em Comunicação Social pela PUCRS.

- Professor do Programa de Pós-Graduação em Processos e Manifestações Sociais da Universidade Feevale.

- E-mail: fernando.antunes@feevale.br

\section{(9) Luis Henrique Boaventura}

- Doutor em Letras pela UPF.

- Mestre em Letras pela UPF.

- Pós-doutorando no Programa de Pós-Graduação em Letras da UPF.

- E-mail: luishboaventura@hotmail.com

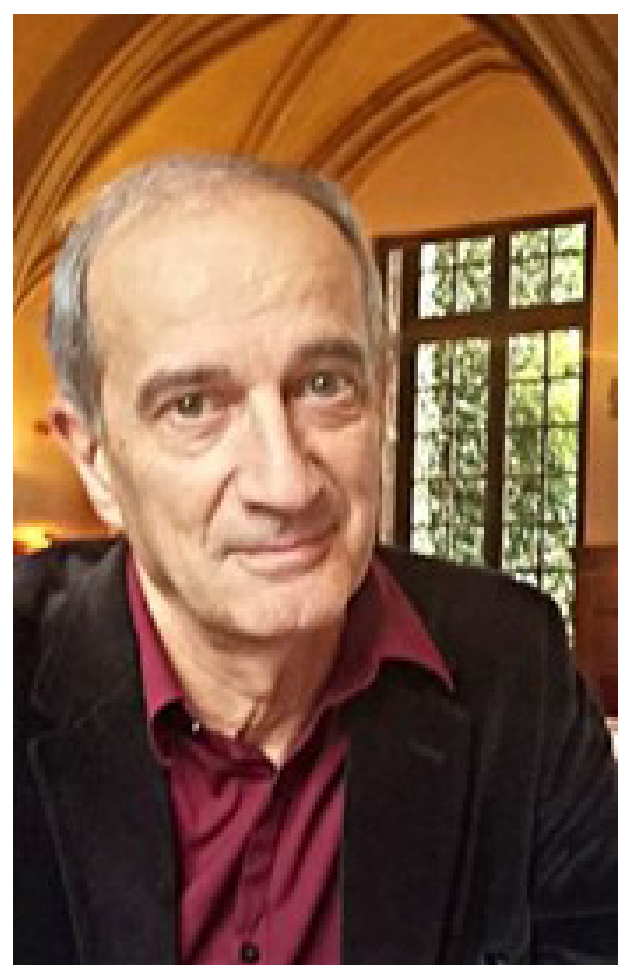

\section{Dominique Maingueneau}

- Professor da Sorbonne Université.

- Pesquisador no Centre d'étude des discours, images, textes, écrits, communications (Céditéc). 
0 entrevistado neste número da ORGANICOM é Dominique Maingueneau, professor emérito da Sorbonne Université (Paris), pesquisador no Centre d'étude des discours, images, textes, écrits, communications (Céditéc). Nosso ilustre convidado conversou por videoconferência com um grupo de pesquisadores do Brasil. Na entrevista exclusiva, conduzida pelos professores Ernani Cesar de Freitas e Rudimar Baldissera, com a colaboração de Fernando Simões Antunes Junior e Luis Henrique Boaventura, o linguista francês discorreu sobre a evolução das teorias de análise de discurso, estabeleceu diferenças epistemológicas entre comunicação e discurso, problematizou a questão da ética do discurso organizacional e fez considerações importantes sobre a pandemia da covid-19 como fenômeno discursivo.

ORGANICOM - Dominique, seus estudos têm sido muito referenciados e usados no Brasil para pensar o discurso organizacional. 0 conceito de ethos discursivo, por exemplo, ajuda muito na compreensão dos fenômenos de formação da imagem organizacional, da imagem pública e da reputação de pessoas e instituições.

DOMINIQUE MAINGUENEAU - Eu não sou um especialista da comunicação organizacional, mas é verdade que existe uma forte compatibilidade entre minha concepção de discurso e a pesquisa sobre organizações. Estou pensando particularmente no conceito de "instituição discursiva". Isto é ainda mais óbvio com a noção de ethos discursivo, que permite a articulação de normas sociais e comportamentos verbais.

ORGANICOM - Dominique, você poderia, a partir dos seus contatos e participações em um significativo número de eventos acadêmicos brasileiros, discorrer sobre a evolução dos estudos que utilizam sua Teoria de Análise do Discurso no Brasil, em diferentes áreas do conhecimento, por exemplo: na comunicação, na linguística e na literatura?

DOMINIQUE MAINGUENEAU - É muito difícil, no meu caso, fazer um traçado, porque o Brasil é um país significativamente grande. Eu conheço só algumas universidades. Além disso, não vou ao Brasil todos os anos. É muito confuso na minha memória. Mas, de fora, uma característica marcante é o número de pesquisadores em discurso que existem no país. Creio que é porque os estudos de discurso no Brasil abarcam áreas do conhecimento que estão em disciplinas diferentes em outros países: semiótica, cultural studies, comunicação... Acho que outra razão é porque o Brasil, como a América do Sul, está ligado aos Estados Unidos e, ao mesmo tempo, à Europa. É uma encruzilhada; pode receber correntes que vêm de muitos países. No entanto, o que mais me chama atenção não é o número de pesquisadores, é sobretudo a diversidade acerca dos temas e das áreas de estudo. Por exemplo, na América do Norte, nos EUA, a área do discurso é ligada à antropologia, à análise da conversa. Há pouca preocupação sobre gênero. Na Europa é muito diferente, mais próximo do que ocorre no Brasil, onde há uma abertura do interesse. No Brasil você tem pessoas que pesquisam sobre discurso religioso, literatura, mídia, gênero, política, educação, justiça. Deve ser o único país no mundo que tem tanta abertura nos estudos do discurso. Há espaço para pesquisas originais, favorecidas por um sistema universitário com três redes de educação: a estadual, a federal e a particular. Isso dá mais competição, mais diversidade.

É mais difícil na França, que é um país muito centralizado. A diversidade é muito menor, e a grande maioria dos pesquisadores em análise do discurso trabalha com as mesmas ferramentas. No Brasil você tem a análise crítica do discurso, a análise bakhtiniana, a abordagem sociopragmática, a abordagem pecheutiana etc. Algumas correntes só existem aí. Por exemplo, a chamada escola francesa de Pêcheux. Na França, Pêcheux não é uma corrente à parte. Quando conheci Pêcheux, para mim, era um dos teóricos da análise do discurso, mas não era um teórico separado dos outros teóricos franceses. 0 Brasil 
também é o único país onde a análise do discurso possui uma corrente bakhtiniana. Em outros países ele é muito estudado, mas somente como um teórico. Isso prova que há muita criatividade no Brasil.

A posição da minha abordagem no campo brasileiro não é simples. Não há nenhuma incompatibilidade teórica com alguns autores como Bakhtin, exemplificando. Talvez o que se torna mais específico sobre a forma como pratico a análise do discurso é que tenho uma visão muito empírica sobre ele. Fabrico conceitos para categorizar e analisar os fenômenos. A consequência desta atitude é que há muitas pessoas que não aderem aos meus pontos de vista sobre discurso e análise do discurso, mas usam meus conceitos para analisar corpora.

ORGANICOM - Em um processo comunicativo, considerando a cena de enunciação e suas três cenas: englobante, genérica e cenografia, como pensar a inter-relação entre essas cenas na construção do ethos discursivo como imagem de si? Como a noção de ethos se relacionaria a uma visão da ética na comunicação institucional? E, nesse sentido, trazemos um fragmento de um artigo que você publicou na revistaEstudos da Língua(gem), em 2020, cujo título é "Comment ne pas etre "pigeonholed"; l'ethos entrepreneurial". Você comenta que "esse ethos coletivo é particularmente importante no mundo contemporâneo. 0 ethos empresarial que supostamente anima os atores mais prestigiados da economia, especialmente aqueles que trabalham no mundo das startups". Como delimitar essa noção de ética na comunicação organizacional?

DOMINIQUE MAINGUENEAU - As noções de ethos e de ética têm a mesma raiz grega. Na nossa visão, a "ética" é algo transcendente, e o ethos é mais uma noção social. Mas no mundo grego essa oposição não tinha sentido. É verdade que é difícil separar os dois conceitos, porque ethos é basicamente um problema de conformidade com normas. Por exemplo: por que um político quer parecer honesto, sincero, patriota? Não é um fenômeno psicológico; é porque, no estereótipo normalizado do bom político, é preciso ser honesto, sério etc. A ética está incorporada ao ethos. É impossível imaginar o ethos sem normas, sem ética. Quando você faz uma entrevista com um jornalista, se você for um político, é preciso ser claro, cortês; de certo modo, você precisa se conformar a uma ética. Mas também é uma prescrição do gênero. Se você não for cortês, sua fala será desqualificada. Isso significa que o ethos carrega espontaneamente um sentido ético.

0 artigo de que você está falando trata do ethos empreendedor, do ethos dos trabalhadores da nova economia. Esse ethos funciona como uma ética. A pessoa que adota essa ética se integra à comunidade e, ao mesmo tempo, pretende ser uma boa pessoa, que faz coisas interessantes para a comunidade. Não se pode imaginar o ethos fora da comunidade. Isso implica que a verdadeira ética vai além do ethos. 0 exemplo mais famoso é o de Sócrates: por que Sócrates foi morto? Porque não se conformou ao ethos discursivo. As pessoas que julgaram o Sócrates não queriam matá-lo, elas queriam uma negociação, e se ele tivesse se comportado como um acusado tradicional, não teria sido morto. Nesse caso, Sócrates saiu do ethos "normal" de uma pessoa julgada e encarnou um outro ethos (no caso de Sócrates, um ethos "filosófico"). Essa discrepância do ethos filosófico dentro de uma instituição judicial é um fenômeno ético. 0 ethos ordinário é uma ética, digamos, inferior, uma ética de conformidade.

ORGANICOM - Fazemos referência neste momento, em especial, a duas importantes publicações recentes de sua autoria: "Retorno crítico à noção de ethos", artigo publicado em 2018 na revista Letras de Hoje, e Variações sobre o ethos, livro publicado pela editora Parábola, em 2020. Quais foram os avanços e reformulações teórico-conceituais que ocorreram em relação à noção de ethos nessas publicações? 
DOMINIQUE MAINGUENEAU - Vou destacar dois pontos. Nesse artigo procurei dividir a noção um pouco vaga de ethos entre três dimensões: ethos "categorial", "experiencial" e "ideológico". Se você não faz uma diferença entre ethos comunista, ethos de pai, ethos honesto... a noção fica um pouco confusa. Em algumas situações, o ethos ideológico tem um papel menor. Em outras, o ethos experiencial é fundamental; exemplificando: na publicidade, quase todo ethos é experiencial: uma maneira de se comportar dentro do mundo.

O segundo ponto é o problema da interpretação do ethos. Quando eu leio pesquisas sobre o ethos, o que me chama atenção é que os analistas parecem acreditar que não há nenhum problema para identificá-lo. 0 problema é que eles sempre estudam textos de políticos, de professores, de jornalistas, locutores que são peritos, que dominam a linguagem - são textos que se podem posicionar dentro de um campo bem definido. Identificamos com facilidade o ethos dos políticos porque sabemos onde se situa a pessoa que está falando e para quem e em que situação está falando; se você sabe isso tudo, deduzir o ethos é fácil. Mas no exemplo dos anúncios nos sites de relacionamentos [presente no artigo publicado na Letras de Hoje] é muito diferente. Para as pessoas que escrevem, mostrar o próprio ethos através do anúncio é muito importante; porém, muitas vezes, é quase impossível identificar o ethos do locutor, porque não há esses pontos de referência, como o campo político, a imagem do político, o gênero de discurso... Todos esses parâmetros, quando não estão presentes, tornam a identificação do ethos um processo difícil. Na vida cotidiana é assim. Estamos sempre com dúvidas sobre o modo de interpretar o ethos dos locutores. Meu propósito foi mostrar que a interpretação do ethos é um problema.

Por sua vez, o livro Variações sobre o ethos tem muito mais elementos do que o artigo, então é difícil sintetizar. Vou destacar alguns pontos.

0 primeiro é a concepção que podemos ter do ethos, porque muitos artigos trabalham, por exemplo, sobre o ethos de Dilma, de Bolsonaro etc. Mas tenho a impressão de que muitas vezes há uma confusão entre imagem e ethos discursivo. É verdade que cada pessoa na vida midiática tem uma imagem: esse estereótipo é o vínculo entre o público e a pessoa. Quanto ao ethos discursivo, não é a imagem de pessoa, mas a imagem que decorre dos discursos dessa pessoa, segundo os gêneros, as situações. A imagem faz parte do ethos prévio, mas não é o ethos discursivo. Para mim, o ethos discursivo é uma faceta, uma dimensão da enunciação, não é um perfil psicológico. Muitas pessoas acreditam que todas as pessoas têm o próprio ethos, como se fosse uma camiseta. Se alguém está falando ou lendo um texto, também está construindo o ethos; contudo, o ethos não é uma noção independente do processo da enunciação.

O segundo ponto, em relação ao livro, é o caráter estratégico da análise do ethos, porque muitas vezes as pessoas estudam 0 ethos considerando que é preciso estudar o ethos. No entanto, na análise do discurso nada é necessário. Estudar o ethos do autor de um artigo de química, de física é geralmente pouco interessante. Quando você estuda o ethos de um escritor, se esse ethos não for integrado à narração e ao gênero do discurso, para que serve? Antes de estudá-lo, é sempre preciso mostrar que é interessante estudar o ethos neste corpus. 0 ethos não é uma entrada muito eficiente para todos os textos. É sobretudo produtivo quando se pode mostrar que participa de um posicionamento, de uma legitimação etc.

0 terceiro ponto é que é preciso não "psicologizar" demais o ethos. A noção de ethos é muitas vezes interpretada como um conjunto de características psicológicas: honesto, apaixonado etc. Mas, em grego, o ethos é um comportamento, uma atitude, não é uma situação psicológica. Nessa perspectiva, nesse livro, procurei mostrar também a importância do que chamo "agenciamento". A disposição dos corpos e a organização do espaço constringem o ethos. Este não é só uma relação entre duas pessoas, um interpretante e um produtor; tem a ver com a organização do espaço da fala, tem a ver com a tecnologia. Nesse sentido, procuro mostrar a relevância do microfone para a análise do ethos. Se não há microfone, o ethos é sempre enfático, você tem que gritar para ser ouvido; mas se existir microfone e você gritar, o efeito é catastrófico. Da mesma maneira, as telas grandes dos meetings modificam totalmente a relação entre o corpo do artista, do político e o corpo do ouvinte. 
Nesse livro também estudo a modificação de uma oração na Igreja Católica. Procuro mostrar que não basta estudar a modificação do texto: é preciso entender que ela está ligada a uma modificação do espaço, da organização litúrgica, e se você considera apenas o que passa na mente do falante e do ouvinte, você não entende nada. Na escola, a relação entre 0 professor e o aluno depende muito da organização do espaço. Isso é, para uma vez mais, retomar o que estava dizendo antes: o ethos é uma faceta da enunciação, e a enunciação não é somente palavras; implica um dispositivo de comunicação.

ORGANICOM - Você tem uma obra clássica, Gênese dos discursos; em especial, o capítulo referente à Semântica Global. Em 1997, na primeira edição brasileira de Novas tendências em análise do discurso, você traz explicitamente as noções de cena de enunciação, de cenografia e de ethos. Para esclarecer algumas questões e estudos que encontramos aqui no Brasil, você poderia comentar sobre qual é a relação entre a Semântica Global e esses princípios organizadores de uma análise sob a lente da cenografia e do ethos? Como um serve ao outro ou que relações poderiam se fazer? Ao falar sobre o ethos, devo falar sobre os sete princípios organizadores da Semântica Global?

DOMINIQUE MAINGUENEAU - A Semântica Global é uma noção dedicada ao estudo de certos tipos de discurso: político, religioso, literário etc. Discursos com campos simbólicos. A relação entre a Semântica Global e o ethos e cenografia é bastante simples: a Semântica Global funciona como uma espécie de filtro para todas as manifestações do discurso: ou seja, se você é um ativista anticapitalista etc., você não vai fazer uma reunião com jornalistas em um hotel de luxo. Esse tipo de gênero de discurso é excluído pelo próprio posicionamento. Da mesma forma, uma cenografia com um ethos profético não corresponde a todos os tipos de religião. Os evangelistas usam muito o profetismo, mas na igreja católica é excluído. Você não imagina um católico durante a missa dizendo que Deus está falando através dele. A Semântica Global serve para limitar as opções e os parâmetros: o ethos, o gênero do discurso, a cenografia etc.

ORGANICOM - Você tem conhecimento de como estão sendo as apropriações da sua teoria no âmbito da comunicação?

DOMINIQUE MAINGUENEAU - As noções de "comunicação" e de "discurso" não estão no mesmo nível. A comunicação é um dado empírico. Está em toda parte. As árvores comunicam, os seres humanos comunicam. Mas o discurso tem outra acepção: é uma maneira de entender a comunicação. Muitas pessoas acreditam que o discurso se configura nos textos empíricos, dados. Em parte, isso é verdade, mas se você fala do discurso midiático, por exemplo, você não está só designando uma certa área de produção verbal, mas também está dizendo "vou entender esta área enquanto discurso", como o ponto de vista da análise do discurso enquanto ação e interação dominadas pelo interdiscurso, pela rede de normas, pela instituição de fala. Essa ambiguidade do termo "discurso" - dado empírico e ponto de vista - é fundamental. A abordagem discursiva descarta a ideia de que a comunicação é uma estratégia na mente de uma pessoa, um plano para convencer um público-alvo. Essa visão muito empresarial ou retórica da comunicação dificilmente é compatível com a análise do discurso.

Na análise de discurso dois modelos da comunicação predominam. 0 primeiro é o modelo interacionista, microssociológico, em que a comunicação é uma troca imediata, oral entre dois indivíduos ou mais. 0 segundo modelo, mais europeu, é o modelo da comunicação através de gêneros do discurso, de dispositivos de comunicação. Este é um modelo que eu considero excelente e que desenvolvo em meu próprio trabalho. Mas, a meu ver, há um perigo: acreditar que é válido para tudo. Exemplifico: uma aforização não é um texto associado a um gênero. Não se pode reduzir a enunciação de uma frase à enunciação de um texto. 
Outro problema é o que eu chamo de "enunciadores aderentes". Quando algo está escrito num objeto, por exemplo, quando você vai a um museu e há uma etiqueta com informações sobre o pintor e a obra exposta. Como dizer que há uma comunicação entre um sujeito e outro? Não tem sentido. Se você está na rua e vê algo escrito numa camiseta, quem está falando? Você acredita que é a pessoa que a veste? É um tipo de comunicação muito especial e muito comum hoje.

Outro exemplo é a religião, quando você diz "Deus nos fala através da Bíblia", o que significa falar? Como Deus fala? Deus não é um locutor. No mundo atual, muitas guerras são religiosas, mas poucos estudiosos perguntam por que, nos dispositivos discursivos, os ativistas pensam que Deus está falando com eles. Mas como Ele fala? É uma forma de comunicação, mas o modelo tradicional não é capaz de descrever esse fenômeno.

Isso tudo para dizer que é normal que um modelo de comunicação domine, porém não é adequado para explicar tudo. Devemos levar em conta que tudo não pode ser reduzido a um modelo midiático e político da comunicação.

ORGANICOM - Com base no que você comenta, comunicação e discurso então não podem ser entendidos como sinônimos...

DOMINIQUE MAINGUENEAU - Para mim é fundamental a diferenciação entre comunicação e discurso: senão, qualquer pessoa que comente algum texto estaria fazendo análise do discurso, e isso não é verdade. Uma pessoa que faz física não é uma pessoa que estuda a matéria: é uma pessoa que estuda a matéria "de um certo ponto de vista". É outro fato, acontecimento. A alquimia também estudava a matéria, mas não era física.

Duas pessoas na rua é comunicação. Mas quando os alunos vão para um departamento de comunicação na universidade, aí se fala da mídia, da publicidade, da internet etc. Os programas de pesquisa da comunicação que existem em quase todas as universidades do mundo não servem para estudar a comunicação, porque estudam um certo tipo de comunicação aplicada sobretudo à mídia. 0 modelo da comunicação publicitária, da comunicação empresarial, da comunicação midiática ou política é tão forte que a tentação é considerar que todos os fenômenos correspondem a essa imagem da comunicação.

Muitas vezes a comunicação que é ensinada na universidade, nas escolas de comércio ou de jornalismo é uma comunicação estratégica. Você quer transmitir uma mensagem e você tem que mobilizar os meios pertinentes para chegar à realização do objetivo. Mas essa visão é totalmente ligada a um tipo de comunicação. Vejamos: quando você conversa com alguém, qual é o propósito da comunicação? Na retórica, temos a impressão de que o sujeito sabe o que quer dizer, a quem está falando e de que está falando. 0 que teóricos como Pêcheux mostram é que o sujeito está dominado pelo sistema. Ele não é o mestre do sentido. Acho que é preciso manter essa distinção entre os dois sentidos de "comunicação": a comunicação aplicada, ensinada, e o fenômeno mais geral da comunicação. Devemos, enquanto estudiosos da análise do discurso, manter essa distinção e evitar que a contaminação de um pelo outro seja demasiado forte, apesar de essa contaminação ser inevitável em algum nível.

ORGANICOM - Gostaríamos de ouvi-lo discorrer um pouco a respeito dos acionamentos discursivos na constituição da opinião pública. Como o discurso, por exemplo, de governos e de grandes organizações vão acionando determinados sentidos com intenções muito claras de gerar opinião pública que, embora fundamentada em informações, na prática, constitui-se em opinião suportada na ignorância, na desinformação? 
DOMINIQUE MAINGUENEAU -É difícil falar do discurso em geral, porque a cada sociedade corresponde uma certa paisagem da fala. Por exemplo, nos países comunistas o partido comunista tinha o monopólio total da palavra pública, e não havia nenhum outro organismo legítimo que tivesse a possibilidade de se dirigir ao público. Isso também gerou uma produção intensa de textos escondidos, paralelos, que circulavam. No mundo atual, a própria noção de paisagem discursiva é problemática. Hoje, com as redes sociais e com a manipulação feita por empresas ou serviços secretos de outros estados etc., quem pode gerar realmente a opinião? Muitas vezes, na internet, quando há um artigo crítico sobre a Rússia, ou China, sempre existem comentadores que defendem o ponto de vista do governo russo e do chinês. E minha reação é: "alguém está sendo pago para isso". No entanto, não posso ter certeza. A paisagem discursiva é muito mais confusa do que antes.

Há tantos atores ocultos envolvidos na elaboração e na circulação de enunciados que entramos em uma crise da interação entre discurso e opinião. E a opinião é cada vez mais difícil de determinar. Antes era muito mais simples: havia o governo, os partidos de oposição e basta. A imprensa era associada mais ao governo ou menos, mais a tal partido ou menos. Inclusive os jornais hoje têm duas facetas: o jornal impresso e o website; mas um website está sujeito a restrições específicas: ele contém comentários de usuários da internet. Estamos em uma situação nova e precisamos de novos conceitos para descrevê-la.

ORGANICOM - Como pensar os acionamentos discursivos, realizados por diferentes organizações (OMS, governos, organizações de mídia, e organizações privadas), no atual contexto de pandemia?

DOMINIQUE MAINGUENEAU - A pandemia oferece um tipo de laboratório para a reflexão sobre o discurso. Nunca na história tivemos uma proliferação tão intensa de enunciados sobre um mesmo tema. Foi uma saturação quase total tanto da fala privada quanto da fala pública. Não está certo que os conceitos habituais da análise do discurso seriam suficientes para analisar esse fenômeno novo. $\mathrm{O}$ segundo aspecto interessante é a resistência da sociedade a abordagens discursivas. $\mathrm{Na}$ França, todo dia, na rádio, na televisão, na imprensa, se falava do vírus com peritos, biólogos e médicos entrevistados. Mas nunca os jornalistas pensaram que a pandemia era também um fenômeno discursivo. Para eles, a pandemia era um fenômeno meramente biológico e medicável, mas era também um fenômeno sociológico, econômico, psicológico. Toda hora surgiam questionamentos sobre como as pessoas iriam aguentar a quarentena, como esse convívio iria modificar e impactar a família etc.

Contudo, a pandemia é basicamente um fenômeno discursivo porque, na verdade, ninguém "vê" uma pandemia. Você vê o vizinho que está doente, mas como se "vê" a pandemia? A pandemia existe porque há organismos que falam dela, tem a mídia que faz circular a informação, que publica mapas, estatísticas, gráficos.

Quando eu tinha 18 anos, havia a gripe de Hong Kong em todo o mundo. Descobri só há três meses que essa gripe matou, em toda a França, no período de dois meses, cerca de 40 mil pessoas. Eu morava em Paris, e eu não sabia que havia uma pandemia grave. Você imagina? Morreram 40 mil pessoas em dois meses, mas só muitos anos depois é que houve estatísticas sobre 0 número de mortes e mapas da epidemia. A pandemia da gripe de Hong Kong não chegou a ser um discurso hegemônico na mídia. Foi uma realidade médica, social, mas não foi uma realidade discursiva forte.

Isso chama a atenção. Há uma resistência profunda da sociedade à dimensão discursiva do mundo social. Para a sociedade, 0 mundo são coisas, e a linguagem que fala sobre essas coisas. No entanto, o discurso como realidade ao mesmo tempo social e verbal é um fato demasiado oposto à visão espontânea. Quando se fala da OMS, dos governos e da comunicação institucional, temos a impressão de que esses organismos falam de uma coisa fora do discurso, mas na verdade essas organizações fazem parte do discurso da pandemia. 
Esta pandemia modificou a legitimidade dos atores e o modo de circulação da informação. Como eu disse antes, é incrível o número de peritos que se viu na televisão, na rádio etc. Ao mesmo tempo, a exigência de buscar a autoridade de um perito ocorreu paralelamente a uma deslegitimação dos cientistas. Isso não é um fenômeno psicológico, é um fenômeno discursivo. As pessoas não acordaram num dia acreditando na ciência e no outro dia duvidando dela. Se descobriram que a ciência "não era tão válida" é porque houve uma modificação da temporalidade de produção do saber científico. Antes se fazia uma vacina em cinco anos. Quando se pesquisava sobre um vírus, se escrevia um artigo, era submetido aos pares, e isso levava ao menos um ou dois anos de burocracia científica. Mas, na crise, não houve nenhum filtro. As pesquisas eram colocadas na internet e os jornalistas liam no mesmo ritmo e às vezes até mais rápido que os peritos. Não é que a ciência mudou, o que mudou foi a temporalidade de construção do discurso científico.

Outro aspecto são as redes sociais. Muitas pessoas acham que as informações que circulam nas redes sociais não são sérias. Não é tão simples: há todo tipo de informação nas redes sociais. 0 problema é que elas não são um gênero discursivo, com atores legítimos, ligados a uma institução determinada. Não têm pontos de referência, e isso causa a impossibilidade de separar as bobagens do que é sério. Não é um problema de conteúdo, é um problema de dispositivo de comunicação.

ORGANICOM - Dominique, agradecemos sua atenção e disponibilidade em compartilhar suas ideias e ensinamentos sobre comunicação, discurso e ethos. 